
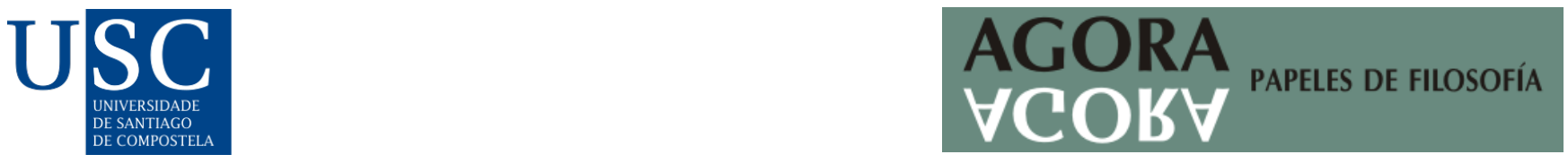

Agora. Papeles de Filosofía, 41(1), 2022. ISSN-e: 2174-3347

https://doi.org/10.15304/agora.41.1.7591

\title{
COMUNIDAD MUNDANA Y COMUNIDAD DE SANGRE EN LA ESTRELLA DE LA REDENCIÓN: UNA APROXIMACIÓN CRÍTICA DESDE LA ANTROPOLOGÍA POLÍTICA DE HELMUTH PLESSNER
}

\author{
Roberto Navarrete Alonso ${ }^{1}$ iD \\ ${ }^{1}$ Universidad Complutense de Madrid, España
}

Recibido: 20/03/2021; Aceptado: 30/06/2021

\section{Resumen}

El estudio ofrece una aproximación crítica a la concepción de la comunidad por Franz Rosenzweig en $L a$ estrella de la redención a partir de la antropología política de Helmuth Plessner. En primer lugar, se presenta la crítica de Plessner al radicalismo social, así como a la impoliticidad del espíritu alemán y su paralelismo con el espíritu judío. En segundo lugar, se estudia el paso de Hegel und der Staat a la Estrella a partir de la clave comunitaria. En tercer lugar, se estudia la diferencia entre comunidad de sangre y comunidad de fe en Rosenzweig, así como su traducción teológico-política en la distinción entre el pueblo eterno y los pueblos del mundo. Por último, a modo de conclusión, se pone de manifiesto la impoliticidad de la propuesta rosenzweiguiana, así como, por tanto, su incapacidad para dar una respuesta al problema político en Weimar, cuyas catastróficas consecuencias Rosenzweig no conoció.

Palabras clave: sociedad; comunidad; política; religión; sangre.

\begin{abstract}
This study offers a critical approach to the conception of community by Franz Rosenzweig in The Star of Redemption from Helmuth Plessner's Political Anthropology. In the first place, Plesser's critique of social radicalism is presented, as well as the impoliticity of the German spirit and its parallelism with the Jewish spirit. Second, the passage from Hegel und der Staat to The Star is studied from the community key. Third, the difference between the community of blood and the community of faith is studied in Rosenzweig, as well as its theological-political translation in the distinction between the eternal people and the peoples of the world. Finally, as a conclusion, the impoliticity of the Rosenzweigian proposal is revealed, as well as, therefore, its inability to give an answer to the political problem in Weimar, the catastrophic consequences of which Rosenzweig did not know.
\end{abstract}

Keywords: society; community; politics; religion; blood. 


\section{INTRODUCCIÓN: RADICALISMO SOCIAL, ANTISEMITISMO Y JUDAÍSMO}

La relación entre comunidad y sociedad representa uno de los más decisivos centros de gravedad en torno a los cuales pivota la reflexión filosófico-política en la Alemania de finales del XIX y principios del XX. Su concepción, en términos de oposición radical, por parte de Ferdinand Tönnies en su gran obra de 1887, Gemeinschaft und Gesellschaft, supuso sin lugar a duda un verdadero hito para quienes le sucedieron. Así, en 1924, Helmuth Plessner (2012, p. 27) comenzaba su Crítica del radicalismo social remitiendo a los planteamientos de Tönnies, si bien para ponerlos en tela de juicio y apostar en cambio, desde el fundamento de su antropología política, por la existencia de una suerte de correlación entre ambas formas de asociación humana: una natural e inmediata, la propia de la comunidad, en la que el individuo quedaba disuelto, y la otra, de carácter artificial, que permitía la salvaguarda de la individualidad amenazada por el ethos comunitarista. Los Límites de la comunidad debían ser establecidos por la sociedad, del mismo modo que los de esta, por su parte, venían dados por la esfera de familiaridad que procura la comunidad; en este contexto, el Estado constituiría la institución jurídica que fungiría como instancia de mediación entre ambas formas de asociación humana (Plessner, 2012, p. 139). De este modo, Plessner abogaba por encontrar una suerte de término medio, de equilibrio, que permitiera la supervivencia de la individualidad sin caer en el atomismo social o, al contrario, que garantizase la existencia de un fondo común sobre el que destaca el individuo singular, sin desprenderse por completo de él. A diferencia de Tönnies, Plessner no consideraba que la Modernidad, en definitiva, desembocase en la destrucción de los lazos comunitarios, sino en una limitación de estos; el mantenimiento de dichos límites, por lo demás, se antojaba crucial en la República de Weimar, a la vista del progresivo ascenso de las opciones más radicales en el Reichstag: los comunitarismos de izquierda, representado según Plessner por el Partido Comunista, y de derecha, capitaneado por el Partido Nacionalsocialista como la más sanguinaria variante, a la postre triunfante, de la Jugendbewegung y de la Revolución Conservadora alemana.

La antropología política de Plessner auspiciaba así una redignificación filosófica de la esfera pública, que gran parte de la intelligentsia alemana había dejado caer en el olvido, y, en particular, una civilización del concepto de lo político de Carl Schmitt, es decir, de la diferencia schmittiana entre el amigo y el enemigo como criterio específico de lo político (Schmitt, 2006, 56 ss.; Plessner, 2018, p. 23). Respecto de lo primero, el blanco de Plessner no era otro que Martin Heidegger, quien en Ser y tiempo había relegado la Öffentlichkeit al ámbito de la impropiedad de la existencia y cuyo Dasein, por tanto, encontraba su realización en la Innerlichkeit, impolítica por definición. Como el propio Plessner se encargó de mostrar en La nación tardía, este gesto era muy propio de la tradición germano-protestante, respecto de la cual Heidegger ${ }^{1}$ bien podía ser considerado entonces su último eslabón -lo cual vale también, no obstante, para el propio Schmitt, cuya reivindicación de lo político comportaba un rechazo tajante de la política entendida como discusión en la esfera pública y, en consecuencia, una reivindicación de formas de asociación o agrupamiento humano que encontraban su base en una homogeneidad o igualdad sustancial del pueblo (Schmitt, 2019, p. 296)-. De hecho, la búsqueda plessneriana de un cierto equilibrio entre la comunidad y la sociedad puede entenderse como la de un equilibrio entre las tradiciones occidental, en particular francesa, y centroeuropea, propia de los pueblos germánicos: entre la civilización y la cultura, por expresarlo en los términos que más tarde serán clave en el estudio de Norbert Elías sobre El proceso de civilización, publicado en 1939. El gesto anteriormente descrito, a saber, el del refugio en la 
interioridad, era en efecto un ademán impolítico, descrito a la perfección por Thomas Mann en sus Betrachtungen eines Unpolitisichen, de 1918: rechazo de la civilización en aras de la cultura, y de la democracia parlamentaria en favor del autoritarismo, pero también de la sociedad civil por mor de la comunidad nacional, que encuentra su realización jurídica -esto es, su representación- en las instituciones del Estado y, en última instancia, en la decisiva y decisoria figura del soberano como encarnación de la vida estatal (Mann, 2009).

Seducido su espíritu por la cultura, la burguesía alemana preferiría la condición de súbdita antes que su implicación en asuntos políticos (Lepenies, 2008). No encontraba en ellos realización alguna, sino tan solo distracción: mera mediocridad mundana, secular, que en absoluto merecía la pena en comparación con las alturas a las que podía conducir una Bildung revestida, cuando menos desde Fichte, del aura de la religiosidad (Koselleck, 2012, pp. 49-93). Nos encontramos aquí también ante la distinción, planteada por Friedrich Meinecke (1911, pp. 1-20) en ese canto de cisne del nacionalismo alemán que fue su Weltbürgertum und Nationalstaat, entre el Estado nacional político, cuya irrupción en la historia dataría de 1789, y el Estado nacional cultural, verdadera aspiración del pueblo alemán que, de acuerdo con cierta metafísica de la historia vinculada a la noción de destino, lo distinguiría respecto del resto de pueblos de mundo. Producto o no de una posible, quizá sólo pretendida -y, por ende, mítica- simbiosis (Traverso, 2005), Plessner encontró aquí una perversa conexión entre los pueblos judío y alemán, tal como lo hizo explícito en los complementos añadidos a la primera edición de lo que con posterioridad se publicó con el título de La nación tardía:

Una y otra vez viene escuchándose que todo el antisemitismo no fue más que simple envidia profesional. Esto es cierto en gran parte, pero no explica la naturaleza específica del enmascaramiento y la justificación ideológicos. A esta naturaleza podemos acercarnos más si hablamos de competencia en un sentido más profundo, teniendo en cuenta no tanto el negocio o el estatus, sino el destino de los dos adversarios. Ambos son "pueblos" y más que Estados. Ambos son, en su desequilibrio con respecto al Estado y en su situación de espera impuesta por la historia, testigos de un mundo pasado que ha desaparecido y garantes de un orden mundial todavía por venir. Ambos son infelices y en ello radica su grandeza: son de anteayer y de pasado mañana, sin descanso en el presente. (Plessner, 2017, p. 196)

Frente a las explicaciones materialistas del antisemitismo, Plessner presenta aquí un motivo de naturaleza espiritual, filosófico-histórica, que apunta a la existencia de cierta comunidad esencial entre germanidad y judaísmo: ambos pueblos compartirían un carácter tanto metahistórico como metapolítico que habría permitido a los judíos alemanes sentirse especialmente cómodos en el contexto de la cultura alemana, con independencia incluso de los tradicionales pogromos antijudíos y de su emancipación política. Sin embargo, esta podría haber sido suficiente en un Estado nacional de base fundamentalmente política como la República Francesa, mientras que en Alemania resultaba accesoria, extrínseca: la germanidad de los judíos alemanes no se cifraba en su condición de Staatsbürger, despreciada por el propio pueblo alemán, sino en su asimilación a la Kultur germano-protestante. Las infames proclamas sobre el parasitismo de los judíos alemanes no habrían tenido tanto que ver, en lo esencial, con aspectos económicos y profesionales, sino culturales, es decir, con una supuesta judaización del Volksgeist alemán. No es, de hecho, una lógica extraña a la del sionismo cultural, dotado de especial relevancia en la Alemania weimariana: adversarios del asimilacionismo que representaba, sin ir más lejos, Hermann Cohen, intelectuales como Martin Buber o Gershom Scholem vieron en esta aculturación una germanización y cristianización del pueblo judío contrarias a su propia existencia como comunidad nacional dotada del singular destino que le conferiría su condición de pueblo elegido. 
Franz Rosenzweig, a cuya concepción de la comunidad está dedicado este trabajo, fue bien consciente de la disolución del judaísmo alemán a la que conducían posiciones como la de Cohen, quien sin embargo había sido su maestro en el estudio de las fuentes de la tradición judía. A diferencia de Buber o Scholem, no obstante, no optó por el retorno a Palestina como medio para la recuperación de la vida judía, sino por una des-asimilación (Dissimilation) de los judíos que tuviera lugar en el seno mismo de Alemania ${ }^{2}$. Su aportación, en este sentido, vino dada por la fundación de una verdadera comunidad de estudio, la Freies Jüdisches Lehrhaus, en la ciudad de Frankfurt, que hiciera frente a la tendencia asimilacionista de la decimonónica Wissenschaft des Judentums. El establecimiento de la Lehrhaus significó sin duda un momento determinante en la trayectoria vital e intelectual de Rosenzweig y dio pie a la interpretación póstuma del autor de La estrella de la redención como maestro del judaísmo, a lo cual contribuyó asimismo, en igual o mayor grado, su colaboración en la Verdeutschung de la Biblia hebrea junto con el propio Buber. El proyecto educativo rosenzweiguiano quería ser en buena medida una puesta en práctica de la concepción del judaísmo expuesta por Rosenzweig en su obra capital. De ahí que, precisamente, su creación no tuviese pretensión política alguna: su apuesta era de naturaleza estrictamente cultural -una aplicación del ideal de la Bildung a la comunidad judía en Alemania ${ }^{3}$ - y por tanto impolítica, en el sentido antes aludido, como impolítico era el judaísmo rosenzweiguiano en la Estrella. No es en vano, desde este punto de vista, que el estudio e interpretación de la tradición se hubiesen convertido para Rosenzweig, al menos desde el final de la Gran Guerra, en un verdadero refugio existencial en el que poder mantenerse al margen del devenir de los acontecimientos políticos de la época, a cuyo análisis, todavía en 1917, no había dejado de atender (Rosenzweig, 2015). Si el retorno al judaísmo, en 1913, no había sido óbice para que participara en el frente de la Primera Guerra Mundial, fue el propio transcurso de esta el que inclinó por fin la balanza vital de Rosenzweig hacia el Maguén David (Avineri, 1988, pp. 831-838).

El desengaño político que para Rosenzweig supuso la vivencia de la guerra fue decisivo, pues, para su definitiva (re)judaización y, en primer lugar, para la propia redacción de La estrella de la redención -cuyas primeras líneas parecen incluso evocar ciertas experiencias en las trincheras de los Balcanes-. Hasta cierto punto, no es incorrecto sostener que la consumación de lo que había comenzado en la célebre Leipziger Nachtgespräch ${ }^{4}$ con Eugen Rosenstock -con quien más tarde, en plena guerra, mantuvo un apasionante diálogo epistolar sobre la relación entre judaísmo y cristianismo (Rosenzweig - Rosenstock, 2017)- supuso una despolitización del pensamiento de Rosenzweig, aun cuando el tercer libro de la Estrella pueda interpretarse como una crítica (literalmente avant la lettre) de la teología política de Carl Schmitt (Navarrete, 2017a). A menudo, en todo caso, la insistencia en su condición de maestro del judaísmo, favorecida por algunas afirmaciones del propio pensador de Kassel, así como por la política editorial seguida por la familia después de su temprana muerte, y consolidada por la publicación de la única biografía que de él se dispone (Glatzer, 1961), ha procurado olvidar que, en el camino hacia la Estrella, se encuentra una primera gran aportación de Rosenzweig a la historia de la filosofía: su libro sobre la idea estatal en el pensamiento de Hegel, inspirado en el undécimo capítulo del ya mencionado Weltbürgertum und Nationalstaat de Meinecke, quien a la sazón supervisó, en calidad de Doktorvater, el trabajo del joven historiador de las ideas que fue Rosenzweig antes del estallido de la Primera Guerra Mundial. Resultaría injusto ubicar al autor de Hegel und der Staat entre los defensores de las ideas de 1914, pues jamás defendió posiciones nacionalistas e incluso su propia interpretación de las ideas políticas hegelianas, contra la lectura, entre otros, de Meinecke, abogó por una revisión de 
la caracterización del filósofo de Stuttgart como pensador nacional alemán (Rosenzweig, 2010, pp. 526-533). Sin embargo, su aproximación al problema (im)político de la comunidad vino dada precisamente por su estudio de la filosofía del Estado en Hegel y, por tanto, está mediada por la larga tradición que Plessner, como ya sabemos, identificó como motor del que terminó por ser $E l$ destino del espíritu alemán al final de su época burguesa ${ }^{5}$. Al margen de los préstamos que Heidegger pudiese haber tomado de Rosenzweig en secreto (Möbuß, 2018), así como de la más que notable diferencia entre ambos en lo que se refiere a la influencia que ejercieron en el panorama filosófico alemán durante la República de Weimar, uno y otro encarnan, desde la germanidad y el judaísmo respectivamente, el mismo «indiferentismo político del espíritu» denunciado por Plessner (2018, p. 123) en los estertores del fallido proyecto democrático weimariano.

\section{SOCIEDAD Y COMUNIDAD: DE HEGEL A LA ESTRELLA}

Si se tiene en cuenta la centralidad del concepto de Gemeinschaft en el pensamiento de Rosenzweig, por no mencionar sin más la destacada posición ocupada por Tönnies en la intelectualidad alemana de la época, resulta llamativo el hecho de que el pensador de Kassel no mencione nunca -en ninguno de sus trabajos publicados, en vida o de manera póstuma- su obra sobre las formas de asociación humana, a la que nos referimos al comienzo de este trabajo ${ }^{6}$. Su desprecio por la sociedad es palmario en La estrella de la redención, donde se refiere a su concepto como «puramente mundanal» (allzuweltlich) (Rosenzweig, 2021, p. 318). En realidad, aparece mencionado tan solo en cuatro ocasiones, una de ellas a propósito de Hegel, por medio de quien, nos dice en Hegel und der Staat (Rosenzweig, 2010, p. 391), la expresión bürgerliche Gesellschaft adquirió su «sentido eminente» (ausgeprägten Sinn), que describe del siguiente modo:

La vida en común [Gemeinleben] de los seres humanos en las grandes asociaciones [Verbände] e incluso en el Estado y más allá del Estado, en la medida en que no era ella misma vida estatal, sino que sólo se encontraba en relaciones más o menos amplias con el Estado. [...] En la sociedad civil rige aquella perspectiva que sólo quiere saber de los individuos independientes, asociados sólo «por las necesidades de los individuos y con un sistema jurídico como instrumento para la seguridad de las personas y de la propiedad, y con una organización externa para sus intereses particulares y comunes». Ella es el «Estado externo», el «Estado de las necesidades», el «Estado del entendimiento». (Rosenzweig, 2010, p. 392) ${ }^{7}$

En cuanto sistema de dependencias recíprocas, como llama Hegel a la sociedad civil, «la economía [...] es su contenido originario» (Rosenzweig, 2010, p. 392). De manera consecuente, en cuanto miembro de la sociedad civil, el ser humano es considerado como «persona», cuya voluntad libre se realiza o existe como propiedad, no como portador del Estado (Staatsträger) o ciudadano (Staatsbürger). Este último no existe como tal en el mundo fenoménico de lo ético que es la sociedad civil, en la que la eticidad pierde el contenido que encontraba en la familia y aparece sólo de manera formal, sino que encuentra su existencia en la unidad sustancial de la comunidad ética en que, como fin en sí mismo, consiste el Estado. En el Estado, por tanto, la voluntad libre del individuo, de la que se deriva la comunidad, «alcanza su supremo derecho, de la misma manera que ese fin último posee el derecho más elevado respecto de los individuos, cuyo deber supremo es el de ser miembros del Estado» (Hegel, 2017a, p. 253). Ya en agosto de 1910, Rosenzweig había dejado constancia en su diario de esta característica de la concepción hegeliana del Estado y de su relación con el individuo: «La verdad del individuo se traslada a la comunidad» (Rosenzweig, 1979a, p. 
106), esto es, al Volk, cuyo espíritu representa el Estado. Entonces, sin embargo, establecía una comparación poco acertada entre los modelos hegeliano y marxiano, como si la única diferencia, a este respecto, entre uno y otro residiese en el carácter material o sensible de la comunidad en Marx, en cuanto «comunidad económica» (Wirtschaftsgemeinschaft). En el texto publicado en 1920, aunque finalizado, en lo esencial, inmediatamente antes del estallido de la guerra en 1914, Rosenzweig (2010, p. 469) corrige esta primera impresión: la sociedad civil, en Hegel, es concebida en términos materialistas, de tal manera que la operación de Marx consistiría en la sustitución del Estado por la propia sociedad civil, así como del credo estatal (Staatsgesinnung) por la conciencia de clase. Quizá pueda valer esto para Marx, empero, en cuanto «fundador de la socialdemocracia» (Rosenzweig, 2010, p. 467), pero desde luego no para esa forma de radicalismo social que representó el marxismo, cuyo ethos comunitarista, a ojos de Plessner, resulta indiscutible.

$\mathrm{Al}$ margen de esta última consideración, en las conclusiones de Hegel y el Estado, añadidas por Rosenzweig al término de la Gran Guerra, y por tanto cuando ya había tenido la vivencia de los estragos provocados por el nacionalismo, el discípulo de Meinecke corregía a su maestro al indicar que, en el camino que condujo de Hegel a Bismarck, los ideólogos del II Reich y, en particular, Heinrich von Treitschke, habrían procedido a una suerte de nacionalización de la idea hegeliana de Estado (Rosenzweig, 2010, pp. 527 ss.). De acuerdo con la interpretación de Rosenzweig, el elemento liberal en la filosofía del Estado de Hegel no tenía conexión alguna con la idea de nación. Hegel y Treischke coincidían al concebir el Estado como meta, pero el primero dirigía hacia ella la voluntad del individuo, mientras que el segundo hacía lo propio con la nación: sólo como filósofo de la historia, no como filósofo del Estado, podría considerarse a Hegel vinculado con la idea nacional. La afirmación de que «el nuevo Reich tenía en su basamento nacional algo que resultaba extraño, o al menos innecesario, al ideal estatal hegeliano» (Rosenzweig, 2010, p. 530) puede considerarse una defensa de Hegel y de las potencialidades de su concepción del Estado, o cuando menos una exculpación respecto de lo acontecido entre 1914 y 1919. Sin embargo, el daño ya estaba hecho: «Estamos en el final. Cuán al final lo sentimos hoy, cuando ha colapsado la época de Bismarck, a cuyas puertas se sitúa la vida de Hegel como el pensamiento ante la acción» (Rosenzweig, 2010, p. 526). Se trataba del final de una época histórica: el largo siglo XIX, como la ha llamado Eric Hobsbawn (1962; 1975; 1987); y del final de un mundo: El mundo de ayer descrito por Stefan Zweig (1947) en sus memorias. Pero también del final de las esperanzas políticas de Rosenzweig, ante el que el discípulo de Meinecke tomó la determinación de obedecer al «"oscuro impulso"» que nombraba con la expresión «"mi judaísmo"» (Rosenzweig, 1979b, p. 680). El colapso del Reich no sólo dejo un campo de ruinas en la historia, sino también en el camino de Rosenzweig: el autor de Hegel y el Estado daba paso así al de La estrella de la redención (Rosenzweig, 2010, pp. 17s.; Rosenzweig, 1979b, pp. 679 s.).

\section{COMUNIDAD DE SANGRE Y COMUNIDAD DE FE}

La cristalización del nuevo pensamiento rosenzweiguiano en su opus magnum significa en términos generales una ruptura con Hegel como culminación de la filosofía clásica alemana y, desde una perspectiva más amplia, del idealismo en su conjunto, al que Rosenzweig se refiere también como denkende Philosophie, tal como esta se habría venido cultivando desde Jonia hasta Jena. Esto no obsta, sin embargo, para que quepa identificar la presencia de ciertos elementos hegelianos en la Estrella, como he mostrado en otro lugar (Navarrete, 2016). Uno de dichos elementos, en absoluto 
accesorio para el sistema de filosofía que representa la obra mayor de Rosenzweig, es la relación entre judaísmo y cristianismo, cuya tematización por parte del joven Hegel (2014, pp. 363-460) en "Jesús y su destino», de algún modo, el filósofo de Kassel invierte. No es esta una cuestión baladí para el tema que nos ocupa. Al contrario, la concepción de ambas religiones por parte de Rosenzweig depende íntimamente de la relación que en ellas se da, a su juicio, entre revelación y comunidad. Así lo expresaba ya antes de la Primera Guerra Mundial, en una entrada de diario fechada el 20 de junio de 1914 a propósito de Hermann Cohen:

El judaísmo tiene su unidad por naturaleza en la sangre, es decir, tras de sí, en la idea a través de la revelación profética, es decir, ante sí. Por el contrario, el cristianismo es iglesia sólo por medio del desarrollo que surge a partir de la persona de Jesús, es decir, debe tener su revelación tras de sí, porque no se trata de una comunidad natural, sino de una comunidad fundada por la revelación. (Rosenzweig, 1979a, p. 158)

En carta a sus padres del 21 de julio de 1916, es decir, todavía dos años después, Rosenzweig insiste en esta misma idea: «Sólo el cristianismo comienza con la convicción; el judaísmo, por el contrario, con la comunidad, y por consiguiente el cristianismo conduce hacia la "comunidad", mientras que el judaísmo [conduce] hacia la "convicción"» (Rosenzweig, 1979a, p. 201). Esta idea, a saber, que el judaísmo es una comunidad natural que se dirige hacia el cumplimiento de la promesa, mientras que el cristianismo es una comunidad fundada sobre la propia promesa del futuro cumplimiento de la comunidad, es la base a partir de la cual Rosenzweig concibe la correlación de ambas religiones como condición de posibilidad de la redención, así como, en consecuencia, sus respectivas relaciones con el mundo. De este modo, cuando se pregunta por «aquello que constituye la comunidad en la comunidad que es la cristiandad» (Rosenzweig, 2021, p. 379), su respuesta es inequívoca: su expansión a lo largo y ancho del mundo por medio de la actividad misional. La cristiandad es una «comunidad de testimonio» (Rosenzweig, 2021, p. 381), a saber, del testimonio de sí misma como único camino que dirige hacia la redención, identificada con la parousia del Cristo:

Al dar testimonio de la comunidad ha de darse simultáneamente testimonio del camino. La comunidad se hace una gracias a la fe testimoniada. La fe es la fe en el camino. Cada uno de los que están en la comunidad sabe que no hay otro camino eterno que el camino por el que él anda. Pertenece a la cristiandad el que sabe que su propia vida está en el camino que lleva del Cristo que vino al Cristo que vuelve. (Rosenzweig, 2021, p. 381)

Esta interpretación del cristianismo está fundada en las palabras que Juan puso en boca del Jesús en el momento de despedirse este de sus discípulos después de la última cena: «Yo soy el Camino, la Verdad y la Vida. Nadie va al Padre sino por mí» (Juan 14:6). Rosenzweig adoptó esta posición respecto del cristianismo desde el principio, es decir, desde el momento en que, luego de haberse resuelto a convertirse a la fe cristiana, tomó la decisión de permanecer en el judaísmo. De hecho, se trata del argumento central de la carta dirigida a Rudolf Ehrenberg el 31 de octubre de 1913, en la que por vez primera informa de este verdadero acontecimiento en su existencia personal. Merece la pena, a pesar de la longitud del texto, reproducirlo in extenso:

El cristianismo reconoce el Dios del judaísmo, pero no como Dios, sino como el «Padre de Jesucristo». Se aferra al «Señor», pero porque sabe que sólo él es el camino hacia el Padre. Permanece todos los días, hasta el final del mundo, como el Señor de su Iglesia. En ese momento, sin embargo, deja de ser el Señor, y también él estará sometido al Padre, y el Padre será -entonces- todo en todo. Estamos de acuerdo en el significado de Cristo y su Iglesia en el mundo: nadie llega al Padre sino a través de él.

Nadie se dirige al Padre, pero la cosa cambia cuando ya no se necesita llegar al Padre, porque ya se está en él. Y tal es el caso del pueblo de Israel (no del individuo judío). El pueblo de Israel, elegido por su Padre, dirige la mirada, con firmeza, más allá del mundo y de la historia, hacia aquel último punto, lejanísimo, en el que este Padre 
suyo, ese mismo será el Uno y el Único (¡«Todo en todo»!). En ese punto en el que Cristo deja de ser el Señor, Israel deja de ser el elegido. En ese Día, Dios pierde el nombre con el que únicamente lo invoca Israel. Dios, entonces, ya no es «su» Dios. Ahora bien, hasta que llegue ese día, la vida de Israel consiste en anticipar ese día eterno por medio de la confesión y de su modo de actuar, en estar en el mundo como señal viva de ese día, como un pueblo de sacerdotes, en santificar el nombre de Dios por medio de la Ley, a través de su propia santidad. (RosenzweigRosenstock, 2017, pp. 19 s.)

Nos encontramos aquí ante la distinción entre «los pueblos del mundo»y «el pueblo llegado a la meta» (Rosenzweig, 2021, p. 365), verdadero núcleo teológico-político de La estrella de la redención y, en esa misma medida, cuestión de capital importancia en relación con la concepción rosenzweiguiana de la comunidad, que aquí nos ocupa. Este elemento teológico-político está ya presente, in nuce, en la recién citada carta, cuando, al comienzo de su rendición de cuentas ante su amigo, Rosenzweig se refiere al «bastón de mando» de la Iglesia y al «cetro quebrado» de la sinagoga. Este esquema aparece desarrollado más tarde, ya en el intercambio epistolar mantenido por Rosenzweig con Rosenstock, antes de encontrar su exposición, finalmente, en el tercero de los libros de la Estrella. Según la interpretación de su autor, el devenir histórico del cristianismo, es decir, de la iglesia, tendría su origen en una «judaización de los paganos» (de los goyim, es decir, de las naciones: ع̌ $v \eta$ ) y habría desembocado en una «cristianización del concepto de pueblo» que Rosenzweig identifica con el nacionalismo (Rosenzweig-Rosenstock, 2017, pp. 95 ss.). Así, este no sería otra cosa que una secularización del contenido judío por antonomasia: la elección que, universalizada y mundanizada, se traduce en «política mesiánica» a través de la identificación de la salus y la fides de los pueblos del mundo, o de una divinización de la civitas terrena (RosenzweigRosenstock, 2017, p. 98). «Nacionalismo significa que los pueblos no sólo creen ser de Dios [...], sino que creen también dirigirse hacia Dios », escribe Rosenzweig a Rosenstock (2017, p. 96), de lo cual se desprende que las comunidades étnicas o nacionales (völkische Gemeinschaften) vendrían a asumir, en una forma mundanizada, el modo de ser de la comunidad en que consiste la cristiandad. 0 , más bien, al contrario: el cristianismo se realiza a través de la «comunidad mundana» (weltliche Gemeinschaft) que es la comunidad nacional. ${ }^{8} \mathrm{Si}$ en un primer momento, como veremos que es el caso de los judíos, los cristianos encontraron su Reino fuera del mundo, conforme a las palabras del propio Cristo, en su estadio final el cristianismo se hace mundo a través de la nación «desde que existe la posibilidad del Estado cristiano, esto es, desde la Reforma» (Rosenzweig, 2014, p. 306).

\section{COMUNIDAD MUNDANA Y PUEBLO ETERNO}

La influencia de la metafísica hegeliana de la historia, cuando no también, al menos en cierta medida, del Estado, es poco discutible en este punto. En su filosofía del espíritu objetivo, o del derecho, Hegel (2017a, §270; 2017b, §552), en efecto, había identificado la religión cristiana, como religión de la libertad, con el «fundamento» (Grundlage) del Estado ético-racional, en cuanto sustancialidad misma de la eticidad que se realiza de manera plena en la institución estatal. Como es obvio, Hegel estaba pensando, al igual que Rosenzweig, en el luteranismo. En realidad, no es sino su interpretación del dístico de Hegel sobre la racionalidad de lo real lo que Rosenzweig pone en juego aquí.

«Lo que es racional, es real» [...] Esto no es válido en general y desde siempre, sino desde que se convirtió en exigencia ética y criterio de las instituciones humanas a través del cristianismo, por medio de la idea del Reino de Dios en la Tierra. Es válido, en realidad, desde entonces, y porque impone a la acción la tarea de realizar la 
razón en el mundo. Así (¡desde entonces!), el conocimiento se enfrenta a la tarea de examinar cómo la razón se ha implementado en la realidad efectiva (¡convertida en tal desde entonces!). Sólo porque lo racional se ha hecho real - principio de la acción -, sólo por ello lo real es ahora racional - principio del conocimiento-. La segunda mitad de la frase, que frente a la propia costumbre de Hegel siempre se presenta como el núcleo de este pensamiento - «la afirmación hegeliana de la racionalidad de lo real» -, es por tanto sólo la consecuencia de lo expresado en la primera parte, la idea revolucionaria en esencia de la realidad efectiva de lo racional. El segundo miembro de la proposición, que fundamenta el conocimiento y muestra cómo se debe entender el Estado de nuestra edad del mundo, presupone la premisa de la interpretación de la historia, la cual expresa el principio ético vital de este Estado. (Rosenzweig, 2010, pp. 355 s.)

Si bien, como vimos con anterioridad, Hegel derivaba la comunidad ética de la voluntad libre del individuo y, en ese mismo sentido, no situaba la nación a la base del Estado, el pensamiento nacionalista alemán sólo necesitó poner a su servicio la filosofía hegeliana de la historia y la relación entre cristianismo y Estado en que se fundaba para convertir la supervivencia de la nación (salus) en objeto de fe (fides), esto es, para divinizar, o espiritualizar, la comunidad nacional, estrictamente mundana en su origen. El Estado, así, se convertía en la instancia de mediación que permitía, al mismo tiempo, la mundanización del espíritu (cristiano) y la espiritualización (cristianización, en definitiva) del mundo (de los pueblos). La absolutización de la comunidad ética del pueblo, ante la cual al individuo sólo le cabe sacrificarse, en la que debe disolverse para realizar el derecho a su propia realización, encuentra de este modo su máxima expresión. En cuanto individualidad, o personalidad, el ser humano no es considerado más que como parte del todo comunitario, tal como de hecho ocurría ya, a juicio de Rosenzweig (2021, p. 78), en la polis griega: «El individuo en la Antigüedad no se pierde [...] en lo común para encontrarse, sino, sencillamente, para edificar la comunidad» y «la comunidad es para el individuo, como tal comunidad suya, algo último, más allá de lo cual le está vedado mirar». La cristianización de las comunidades políticas, de los pueblos y de los Estados, en definitiva, habría añadido un sentido mesiánico a esta «clausura hacia fuera»e «incondicionalidad hacia dentro» (Rosenzweig, 2021, p. 77) propia de toda Gemeinschaft mundana. Desde entonces, no hay diferencia para estos pueblos del mundo entre guerra de fe o guerra religiosa y guerra del Estado o mundana: el Camino hacia la meta que, desde su origen, representa el cristianismo para ellos, deviene en su época final historia universal, cuyos portadores son los Estado (Rosenzweig, 2021, p. 372). La meta hacia la que se dirigen los pueblos del mundo cristianizados se conquista, ya no por medio de la pura actividad misional de la iglesia como testimonio de la fe, sino a través de la (falsa) eternización de las comunidades nacionales que produce el dispositivo estatal por medio de la dialéctica de derecho y violencia, guerra y revolución, en que se funda (Rosenzweig, 2021, pp. 370-372). Sólo de este modo pueden los pueblos del mundo imitar al pueblo eterno que es la comunidad de sangre en que, en la interpretación de Rosenzweig, consistiría el pueblo de Israel.

La comunidad étnica, popular o nacional (Volksgemeinschaft) que también constituye el pueblo elegido se distingue del resto por el hecho de que sólo a ella le basta con dicha comunidad de sangre. No necesita del Estado, ni por tanto de la historia, para encontrar garantizada su eternidad. Sólo en ella sangre y espíritu son una y la misma cosa: sólo ella es tanto pueblo como religión, es decir, pueblo en tanto que religión, y religión en tanto que pueblo, o un pueblo de sacerdotes. Como tal, no tiene voluntad de eternidad, pues esta ya ha germinado en él. Puede, de este modo, abandonar la tierra, cuyo dominio requiere cualquier otra comunidad, cualquiera de los demás pueblos del mundo, «pues no confían estos en la comunidad viva de la sangre que no esté anclada en el firme fondo de la tierra» (Rosenzweig, 2021, p. 334). No deja de ser llamativo el lenguaje que vemos que Rosenzweig emplea en La estrella de la redención, habida cuenta de cuál habría de ser el desarrollo de los acontecimientos en la Alemania en que se publicó la obra. Más aún si tenemos presentes 
las palabras de Plessner acerca del motivo profundo del antisemitismo, antes referidas. Tan solo unos años después, la base ideológica de la estructura de dominación que se propuso el exterminio físico de los judíos europeos apelaba precisamente a la eternidad de la germanidad ${ }^{9}$, identificaba su condición de Volksgemeinschaft con una Blutgemeinschaft y, por último, vinculaba esta sangre a un determinado suelo como su espacio vital. Su guerra, así, era una guerra de religión como la librada por Israel contra los pueblos de Canaán (Rosenzweig, 2021, p. 368).

Sabemos de la perversión del lenguaje que llevó a cabo el III Reich, pero sabemos también de la dimensión mesiánica que adquirió en él la figura del Führer (Klemperer, 2001; Guardini, 1946). Hay algo inquietantemente premonitorio en las consideraciones de Rosenzweig sobre la comunidad. Pero la eternidad y la sangre a las que él se refería para caracterizar la comunidad de Israel nada tenían que ver con el Estado ni con la raza: la superioridad del pueblo judío era para Rosenzweig una superioridad puramente espiritual, es decir, en sus términos, se cifraba en una superior vinculación con las relaciones que, conforme a la figura misma de la Estrella, Dios mantiene con el mundo y con el ser humano; la Volksgemeinschaft del judaísmo es tanto la más próxima a la Creación como a la Revelación y, en esa misma medida, ella y sólo ella está en condiciones de anticipar la Redención a la que los pueblos del mundo (todavía) se dirigen. Se trata de una comunidad tanto metaética, como, por consiguiente, metapolítica y metahistórica; ella es a los pueblos del mundo lo que el sí mismo (Selbst) a la personalidad (Persönlichkeit) (Rosenzweig, 2021, pp. 95 s.). Tal es el sentido del Shemá Israel: «La comunidad fue llamada con un nombre común, y al escucharlo, empezó a existir [war sie da]» (Rosenzweig, 2021, p. 358), del mismo modo que Abraham respondió a la llamada de Dios con las palabras Da bin ich y, así, comenzó también él a existir, renacido como el homo revelationis que es el sí-mismo: el Yo singular humano que escucha y se convierte así en el Tú al que el Yo se revela. Es el milagro de la revelación del amor de Dios a la creación (a través de su pueblo) lo que da cumplimiento a la «vida en común no personal», a esa «comunidad natural de la sangre» que es Israel. La promulgación de este milagro, en la forma del amor al prójimo, anticipa por su parte el «reino de la hermandad» mesiánica de todos los seres humanos a la que también se refiere Rosenzweig (2021, p. 232) como la «alianza en una comunidad sobrenatural»: la humanidad redimida. La pura Blutgemeinschaft en que consiste la Volksgemeinschaft judía representa así, por anticipado, la unidad del género humano, frente al riesgo cristiano de divinizar, con demasiada urgencia, este mundo; por su parte, la cristianización de los pueblos (no de su concepto, por tanto), cuyo cumplimiento consistiría en la unificación del globo terrestre en una Völkergemeinschaft, coadyuvaría en la redención en la medida en que, frente al peligro de un olvido del mundo por parte del judaísmo, recordaría a este que la redención es redención de este mundo y del ser humano en él (Navarrete, 2017b, pp. 196 s.).

\section{CONSIDERACIONES FINALES}

En su crítica del radicalismo social, Plessner (2012, pp. 63-78), a la vista del panorama político de su tiempo, identificó dos posibilidades fundamentales de la comunidad: el origen común de la sangre como idea unificadora del comunitarismo étnico-nacional, por el lado del conservadurismo, y el ideal impersonal de la razón, de acuerdo con Plessner, por el lado del comunismo. Ambas exaltaciones de la esfera de la comunidad, sin las limitaciones impuestas por la sociedad civil, desembocan necesariamente, a su juicio, en violencia: 


\begin{abstract}
En su forma étnico-nacional, la acentuación de la etnicidad conduce a un nacionalismo consciente y a la guerra como posibilidad última de confrontación. [...] En cambio, en su forma internacional tenemos un comunismo antinacional, no étnico y en último término adverso a la sangre, que pretende realizar el ideal pacifista mediante la violencia militar. (Plessner, 2012, p. 70)
\end{abstract}

A la luz de lo anteriormente expuesto acerca de la crítica de Rosenzweig a la "política mesiánica», es sostenible afirmar que el pensador de Kassel suscribiría en términos generales la interpretación del comunitarismo étnico-nacional de Plessner, quien no duda en ningún caso a la hora de vincularlo con el cristianismo de los orígenes, pero ante todo con la Reforma de la Iglesia según el espíritu de los primeros cristianos (Plessner, 2012, pp. 36 ss.). Al igual que Rosenzweig en Hegel und der Staat, Plessner (2012, p. 70) también señala a Treitschke (y, en su caso, a Fichte) como promotores de la cristianización del Estado nacional en Alemania. Al fin y al cabo, por último, el propio Rosenzweig (2005, p. 43) concibió su análisis de la política mesiánica, es decir, del nacionalismo como figura histórica del cristianismo, con una «teoría de la guerra». Como ya sabemos, la judaización de Rosenzweig fue el resultado de su dolorosa experiencia de las consecuencias a las que precisamente condujo el comunitarismo étnico-nacional: el derramamiento de la sangre del pueblo sobre la tierra que le es propia y que como tal se ama, o la «comunidad con lo muerto» en que se traduce el amor a la patria (Rosenzweig, 2021, pp. 334 s.) ${ }^{10}$. Otra forma de amor, el amor al prójimo como a uno mismo, funda en Rosenzweig la comunidad impersonal de la humanidad que anticipa la comunidad sanguínea del pueblo judío; esta comunidad mesiánica es, en cuanto sobre-natural, también internacional, pues se sitúa más allá de toda distinción entre los pueblos, pero también más allá de toda historia. Por este motivo, su símbolo proléptico, si quiere serlo, debe permanecer al margen de la temporalidad histórica, al margen del Estado y, en consecuencia, de la guerra: «El judío [...] es el único pacifista auténtico» (Rosenzweig, 2021, p. 369). La comunidad de sangre del pueblo judío parece situarse así a medio camino entre los ideales de la comunidad étnico-nacional y de la comunidad impersonal a los que se enfrentó Plessner: participa del vínculo sanguíneo, entendido en un sentido mucho más amplio que el propio del naturalismo y el biologicismo, y se funda irracionalmente en el amor, pero apunta hacia una unificación no violenta, metapolítica, de la humanidad toda. No es la razón, sino la fe, el centro ideal e impersonal sobre el que se sostendría; no deja de ser una comunidad existencial, si bien desprovista de centro personal (Plessner, 2012, p. 73).

La concepción rosenzweiguiana del pueblo judío como comunidad (mesiánica) de sangre responde a una estrategia metafísica de retirada respecto de lo político y, en ese sentido, constituye a lo sumo una crítica metapolítica de las consecuencias políticas derivadas de la impoliticidad típica del espíritu alemán. En cuanto retirada respecto de lo político, esta metapoliticidad apenas sí es distinguible de dicha impoliticidad, salvo por el hecho de querer sustraerse también al Estado autoritario en que esta desemboca. Es, así, una suerte de sustracción respecto de la sustracción en que consiste lo impolítico: sustracción respecto de la comunidad de destino que se sustrae a la esfera política en que debe desenvolverse una política democrática fundada en el tacto y la diplomacia (Plessner, 2012, pp. 117 ss.). Como tal, no parece estar en condiciones, como dijo Rosenzweig (1979b, p. 969) pretender, de poner límites a la política; desde luego no de hacerlo de manera activa. Antes bien, una retirada espiritual respecto de la política parece dejar vía libre para que esta incurra en excesos. El destino de las comunidades judías de la Europa oriental, aquellas que no hubiesen necesitado de la des-asimilación propuesta por Rosenzweig al no haber pasado por el momento previo de la aculturación, es un dramático, catastrófico ejemplo de esto. La propuesta de Rosenzweig participa en demasía del propio romanticismo del que se nutre el 
comunitarismo étnico-nacional. Los límites de este, los límites de la comunidad y, en la terminología actual, los límites del populismo que en los últimos tiempos, como en Weimar, ha venido avanzando a diestra y siniestra, son en cambio establecidos por un entramado institucional sólido que garantice formalmente el funcionamiento material de la sociedad civil, sin por ello disolver los lazos comunitarios connaturales al ser humano -vínculos, por lo demás, no necesariamente étniconacionales (Plessner, 2018, 118 ss.)-. En una forma de asociación humana tal podría también existir esa comunidad de sangre, en definitiva, ansiada por Rosenzweig, así como su correspondiente figura de la humanidad, si bien como una más entre las potencialmente infinitas que resultan posibles para la insondable naturaleza del ser humano.

\section{Bibliografía}

Avineri, S., "Rosenzweig's Hegel Interpretation: Its Relationship to the Development of His Jewish Reawakening", en W. Schmied-Kowarzik (ed.), Der Philosoph Franz Rosenzweig (1886-1929): Internationaler Kongreß-Kassel 1986, II, Freiburg-München, Alber, 1988, pp. 831-838.

Casper, B., “Martin Heidegger und die Theologische Fakultät Freiburg (1909-1923)”, en: R. Baümer, K. Suso Frank y H. Ott (eds.), Kirche am Oberrhein. Festschrift für Wolfgang Müller, Freiburger Diözesen Archiv, núm. 100 (1980) 534-541.

Glatzer, N. N., Franz Rosenzweig: His Life and Thought, New York, Schocken Books, $1961^{2}\left(1953^{1}\right)$.

Guardini, R., Der Heilbringer in Mythos, Offenbarung und Politik. Eine theologisch-politische Besinnung, Stuttgart, DVA, Stuttgart, 1946.

Hegel, G. W. F., “Jesús y su destino”, en El joven Hegel. Ensayos y esbozos, ed. de J. M. Ripalda, Madrid, FCE, 2014, pp. 363-460.

Hegel, G. W. F., Fundamentos de la Filosofía del Derecho o Compendio de Derecho Natural y Ciencia Política, trad. de J. Abellán, Madrid, Tecnos, 2017a.

Hegel, G. W. F., Enciclopedia de las ciencias filosóficas [1830], ed. de R. Valls Plana, Madrid, Abada, 2017b.

Hobsbawn, E., The Age of Revolution: 1789-1848, London, Weidenfeld \& Nicolson, 1962.

Hobsbawn, E., The Age of Capital: 1848-1875, London, Weidenfeld \& Nicolson, 1975.

Hobsbawn, E., The Age of Empire: 1875-1914, London, Weidenfeld \& Nicolson, 1987.

Klemperer, V., LTI: La lengua del Tercer Reich. Apuntes de un filólogo, trad. de A. Kovacsic, Barcelona, Minúscula, 2001.

Koselleck, R., "Sobre la estructura antropológica y semántica de la Bildung”, en Historias de conceptos, trad. de L. Fernández Torres, Madrid, Trotta, 2012, pp. 49-93.

Lepenies, W., La seducción de la cultura en la historia alemana, trad. de J. Blasco Castiñeyra, Madrid, Akal, 2008.

Mann, Th., Betrachtungen eines Unpolitischen, ed. de H. Kurzke, Frankfurt a.M., Fischer, 2009.

Meinecke, F., Studien zur Genesis des deutschen Nationalstaates, München-Berlin, Oldenbourg, $1911^{2}\left(1908^{1}\right)$.

Möbuß, S., Sternschatten. Martin Heideggers Adaption der Philosophie Franz Rosenzweigs, Freiburg-München, Karl Alber, 2018.

Navarrete, R., “Disimilación como deshistorización en el pensamiento de Franz Rosenzweig”, Open Insight 6/10 (2015), 109-134.

Navarrete, R., “'Der Jude, der in deutschem Geist macht'. Das Hegelbuch Franz Rosenzweigs und seine Wirkung", Naharaim 10/2 (2016), 273-302. 
Navarrete, R., Los tiempos del poder. Franz Rosenzweig y Carl Schmitt, Madrid, Escolar y Mayo, 2017a.

Navarrete, R., "Globalización y geo(teo)política de la historia: Franz Rosenzweig y Carl Schmitt”, Éndoxa 40 (2017b), 183-202.

Plessner, H., Límites de la comunidad. Crítica del radicalismo social, trad. de T. Menegazzi y V. Granado Almena, Madrid, Siruela, 2012.

Plessner, H., La nación tardía. Sobre la seducción política del espíritu burgués, ed. de J. Fischer y J. L. Villacañas, trad. de K. Lavernia Biblioteca Nueva, Madrid, 2017.

Plessner, H., Podery naturaleza humana. Ensayo para una antropología de la comprensión histórica del mundo, ed. de R. Navarrete y K. Lavernia, trad. de K. Lavernia, Madrid, Guillermo Escolar, 2018.

Rosenzweig, F., Der Mensch und sein Werk. Gesammelte Schriften I: Briefe und Tagebücher 1 (1900-1918) [GSI, 1], Haag, Martinus Nijhoff, 1979a.

Rosenzweig, F., Der Mensch und sein Werk. Gesammelte Schriften I: Briefe und Tagebucher 2 (1918-1929) [GSI, 2], Haag, Martinus Nijhoff, 1979b.

Rosenzweig, F., Der Mensch und sein Werk. Gesammelte Schriften III: Zweistromland. Kleiner Schriften zu Glauben und Denken, Haag, Martinus Nijhoff, 1984.

Rosenzweig, F., "El nuevo pensamiento. Observaciones adicionales a La Estrella de la Redención”, en Á. E. Garrido Maturano (ed.), El nuevo pensamiento. Seis ensayos introductorios al pensamiento de Rosenzweig, trad. de Á. E. Garrido Maturano, Buenos Aires, Adriana Hidalgo, 2005, pp. 11-51.

Rosenzweig, F., Hegel und der Staat, Frankfurt a. M., Suhrkamp, $2010^{3}\left(1920^{1}\right)$.

Rosenzweig, F., “Paralipomena”, en El país de los dos ríos. El judaísmo más allá del tiempo y la historia, trad. de I. Ortega, Encuentro, Madrid, 2014, pp. 227-320.

Rosenzweig, F., Escritos sobre la guerra, ed. de R. Navarrete, Salamanca, Sígueme, 2015.

Rosenzweig, F., La estrella de la redención, ed. de M. García-Baró, Salamanca, Sígueme, 2021.

Rosenzweig, F. - Rosenstock, E., Cartas sobre judaísmo y cristianismo, ed. de R. Navarrete, Salamanca, Sígueme, 2017.

Schmitt, C., El concepto de lo político. Texto de 1932 con un prólogo y tres corolarios, trad. de R. Agapito, Madrid, Alianza, 2006.

Schmitt, C., Teoría de la Constitución, trad. de F. Ayala, Madrid, Alianza, 2019.

Tönnies, F., “Besprechung von Hegel und der Staat”, Zeitschrift für Politik 13 (1924), 172-176.

Traverso, E., Los judíos y Alemania. Estudios sobre la "simbiosis judío-alemana", trad. de I. Sancho García, Valencia, Pre-textos, 2005.

Zweig, S., Die Welt von gestern: Erinnerungen eines Europäers, Frankfurt a. M., Suhrkamp, 1947.

Notas

$1 \quad$ Es de sobra conocido que Heidegger se formó en un ambiente católico, pero también que en su célebre carta de despedida a Engelbert Krebs, del 9 de enero de 1919, decidió renunciar al «sistema del catolicismo» (Casper, 1980, p. 541). En opinión de Plessner, que aquí suscribimos, la analítica heideggeriana del Dasein es en todo caso afín al modo protestante de considerar la existencia individual.

2 A esta disimilación se refiere Rosenzweig, a propósito de su proyecto educativo, al que vamos a referirnos inmediatamente, en una entrada de su diario fechada el 3 de abril de 1922 (Rosenzweig, 1979b, p. 770). Sobre esta cuestión, véase también: Navarrete, 2015, pp. 109-134.

3 Véanse sus textos sobre aprendizaje judío, en: Rosenzweig, 1984, pp. 459-517. 
4 Se trata de la conversación nocturna que provocó en Rosenzweig, impresionado por Rosenstock, la decisión de convertirse al cristianismo y, finalmente, de retornar al judaísmo. Dicha conversación es el telón de fondo del intercambio epistolar al que nos referiremos de inmediato.

$5 \quad$ Tal es el título original, en su versión de 1935, de La nación tardía de Plessner.

6 Rosenzweig ni siquiera tuvo un ejemplar de Gemeinschaft und Gesellschaft en su biblioteca, como muestra el correspondiente registro. Por lo demás, merece siquiera la pena mencionar el hecho de que Tönnies publicara una reseña de Hegel und der Staat en la Zeitschrift für Politik. En ella destacaba de manera implícita la comedida lectura de Hegel por parte de Rosenzweig, sin incurrir en la heroización del filósofo suabo por parte de su primer biógrafo, Karl Rosenkranz, ni en la condena de Rudolf Haym (Tönnies, 1924, pp.173 s.).

$7 \quad$ Las citas de Hegel proceden de los parágrafos 157 y 183 de sus Fundamentos de la Filosofía del Derecho o Compendio de Derecho Natural y Ciencia Política.

8 Esta realización del cristianismo en el mundo, es decir, esta mundanización del cristianismo, debe entenderse, por supuesto, desde el punto de vista de una metafísica de la historia deudora, como señalaremos de inmediato, de los planteamientos hegelianos, y dotada por tanto de un presupuesto escatológico.

9 Dem ewigen Deutschtum puede leerse, sin ir más lejos, en la entrada a la Facultad de Filosofía de la Universidad de Friburgo, en la que Rosenzweig estudió. La inscripción data de 1936 y, por tanto, Rosenzweig, fallecido en 1929, nada pudo saber de ella, aunque sí del pangermanismo, ya presente en su época.

10 También el amor es, para Plessner (2012, pp. 66 ss.), factor de la institución de una comunidad étnico-nacional. 